\title{
DEGRADAÇÃO AMBIENTAL DO RIO PAVUNA-MERITI
}

\section{Marcos Antonio Braga de Barros ${ }^{1}$ \\ Rachel Sampaio de Oliveira ${ }^{2}$ \\ Júlio César da Silva ${ }^{3}$}

\begin{abstract}
Resumo: O Rio Pavuna-Meriti pertence à bacia hidrográfica Pavuna São João de Meriti e banha em seus últimos 7,4km o município de Duque de Caxias, que segundo dados de 2014 do Instituto Brasileiro de Geografia e Estatísticas (IBGE) é a $15^{a}$ maior economia do Brasil. Duque de Caxias sofre constantemente com inundações por conta do assoreamento dos rios, além da falta d'água potável que causam grande prejuízo econômico, sociais e à saúde da população. Os problemas de assoreamento existentes neste rio são comuns em outros rios do Brasil, entre suas principais causas estão o lançamento de esgotos sem tratamento, ausência de coleta de lixo, sem falar dos aspectos indiretos como desmatamento de suas margens, ocupação da calha secundária do rio. As primeiras pesquisas demonstram que apenas um planejamento integrado de uso do solo e recursos hídricos, medidas socioeducativas para a conscientização do despejo irregular de lixo, saneamento urbano, reuso de água de chuva e aumento das áreas verdes com ênfase na permeabilidade do solo, além de vontade política, incentivos e participação popular, podem em simultaneidade mitigar as inundações neste rio.
\end{abstract}

Palavras-chave: Rio Pavuna-Meriti; Assoreamento; Duque de Caxias; Inundações.

\footnotetext{
1 Engenharia Civil/Unigranrio, Brasil. Marcosbarros.rj@gmail.com.

2 Engenharia Civil/Unigranrio, Brasil. rachelsam@unigranrio.edu.br.

${ }^{3}$ Engenharia Civil/Unigranrio, Brasil. jcesarop@gmail.com.
} 